\section{Response: Re: One-View Chest Radiograph for Initial Management of Most Ambulatory Patients With Rib Pain}

To the Editor: We appreciate the thoughtful comments of Drs. Zumblick and Mendes-Marcon regarding the use of point-of-care ultrasound (POCUS) as an alternative to conventional radiology. We are in complete agreement concerning both the efficacy and advantages of ultrasound for the detection of rib fractures and their complications.

The only current limitation to POCUS is the number of primary care physicians who feel comfortable performing these examinations in their offices. Our medical group rolled out POCUS to all of our free-standing clinics in the fall of 2019. However, because of the limited training available to many of our primary care physicians who already carry heavy patient loads, we have not yet seen a significant decrease in the overall number of chest radiographs or rib series for ambulatory patients with suspected rib fractures.

As more primary care training programs incorporate POCUS into their residency, we hope to see an overall decline in any radiograph imaging for ambulatory patients with possible rib fractures.

Alyssa Finger, BS

School of Medicine, Creighton University 5863

Mahimahi Street Honolulu, HI 96821 alyssafinger@creighton.edu

Nishimura Emily, BS

Harris Mark, BS and Yoon Hyo-Chun, $\mathrm{MD}$, $\mathrm{PhD}$

To see this article online, please go to: http://jabfm.org/content/ 33/5/879.full.

doi: 10.3122/jabfm.2021.04.210195 